\title{
Transmission of Tetracapsuloides bryosalmonae (Myxozoa: Malacosporea), the causative organism of salmonid proliferative kidney disease, to the freshwater bryozoan Fredericella sultana
}

\author{
D. J. MORRIS* and A. ADAMS \\ Institute of Aquaculture, University of Stirling, Stirling FK9 4LA, Scotland, UK
}

(Received 28 April 2006; revised 5 Fune 2006; accepted 8 fune 2006; first published online 4 September 2006)

\begin{abstract}
SUMMARY
Proliferative kidney disease (PKD), caused by the malacosporean parasite Tetracapsuloides bryosalmonae, causes significant losses among salmonids in Western Europe and North America. The role of salmonid fish in the life-cycle of this parasite has been conjectured upon for over a quarter of a century. To examine whether fish can transmit the infection to bryozoans, the known invertebrate host, water containing parasitized brown trout Salmo trutta was pumped into tanks containing colonies of Fredericella sultana collected from the wild. The specific parasite-free status of these colonies being first assessed, by PCR and prolonged laboratory culture. After 6 weeks exposure to the brown trout aquarium effluent, portions of these colonies displayed overt infections with T. bryosalmonae. This was in contrast to control bryozoans, derived from the experimental colonies prior to exposure, which remained T. bryosalmonae negative. In addition, spores obtained from the experimentally infected colonies were exposed to naïve rainbow trout, resulting in clinical PKD, thus completing a cycle of transmission. During the experiments, the infection was noted to inhibit statoblast formation within bryozoans and appeared to be pathogenic, finally killing the bryozoan host. These findings indicate that fish can transmit the parasite to bryozoans and are an integral part of this parasite's life-cycle.
\end{abstract}

Key words: PKD, PKX, Tetracapsuloides, Malacosporea, Myxozoa, life-cycle.

\section{INTRODUCTION}

The phylum Myxozoa contains over 2180 species, almost all of which are considered to be obligate parasites of aquatic animals (Lom and Dyková, 2006). It is composed of 2 classes, the Myxosporea and the Malacosporea, members of which are important pathogens responsible for severe economic losses in cultured and wild fisheries (Lom and Dyková, 2006). While the life-cycles of a number of myxosporeans have been elucidated and involve an alternation of hosts between an annelid and fish, to date no malacosporean life-cycle has been completed (Tops and Okamura, 2005).

Tetracapsuloides bryosalmonae is the malacosporean parasite that causes proliferative kidney disease (PKD) in salmonid fish. In Europe and North America, this disease has been a major constraint on the cultivation of rainbow trout Oncorhynchus mykiss and other salmonids for over a quarter of a century. It primarily affects fingerling fish (i.e. those in their first year of contact) and usually results in $100 \%$

* Corresponding author: Institute of Aquaculture, University of Stirling, Stirling FK9 4LA, Scotland, UK Tel: + 441786 467912. Fax: +44 1786 472133. E-mail: djm4@stir.ac.uk morbidity on an affected farm with up to $20 \%$ mortality (Hedrick et al. 1993). Impacts on wild populations are generally unknown but are potentially substantial (Feist et al. 2002; Whali et al. 2002).

PKD is characterized by a chronic inflammation of the anterior and posterior kidney which is caused by a massive accumulation of lymphocytes and extensive granuloma formation (Chilmonczyk and Monge, 1999). The inflammatory response is centred on the interstitial pre-sporogonic stages of $T$. bryosalmonae that undergo extensive proliferation in the fish host (Ferguson and Needham, 1978). Initial studies on these stages could not adequately speciate the parasite leading it to be referred to simply as PKX (Seagrave et al. 1980). Kent and Hedrick (1985, 1986) described renal intra-tubular sporogonic stages, some of which possessed polar capsules and identified the parasite as a member of the phylum Myxozoa. While polar capsules are a distinguishing feature of myxozoan spores, the spores of T. bryosalmonae lacked hard valves and were therefore thought to be immature. Together with the severe inflammation caused by the parasite this led to speculation that salmonids were an aberrant host (Seagrave et al. 1980; Kent and Hedrick, 1986, 1987). However, extensive studies on wild fish populations consistently failed to identify any other 
potential fish host (Hedrick et al. 1986; Feist, 1988; MacConnel and Smith, 1990; Feist and Bucke, 1993; Kent et al. 1993; Kent et al. 1998; Morris et al. $2000 a$ ).

Two papers by Okamura (1996) and Canning et al. (1996) respectively described an unusual Myxozoan parasite Buddenbrockia plumatellae (syn. Tetracapsula bryozoides) infecting the freshwater bryozoan Cristatella mucedo. This parasite formed sacs within the host filled with spores that lacked hard valve cells. Subsequent 18 ssu rDNA analysis and microscopical studies determined that T. bryosalmonae also infected a range of freshwater bryozoans (Anderson et al. 1999; Longshaw et al. 1999). The unusual sporogenesis and cytoplasmic nature of the spores led to the class Malacosporea being erected in the phylum Myxozoa to accommodate these parasites (Canning et al. 2000). Transmission experiments confirmed that spores of $T$. bryosalmonae released from bryozoans could infect salmonids resulting in PKD (Feist et al. 2001). While bryozoan to bryozoan transmission is not known to occur (Tops et al. 2004), the role of salmonids remains in question with $T$. bryosalmonae being reported from bryozoans in lakes with no known salmonid populations (Anderson et al. 1999; Okamura et al. 2001). Furthermore, a series of experiments to transmit $T$. bryosalmonae from infected salmonids to naïve bryozoans failed, leading to the suggestion that fish are either facultative or aberrant hosts and are not essential for the spread of the disease (Tops et al. 2004; Tops and Okamura, 2005).

Here we provide evidence that transmission of $T$. bryosalmonae from a salmonid to a bryozoan does occur, thus completing the first life-cycle of a malacosporean parasite and indicating that native salmonids are an important part of this parasite's life-cycle.

\section{MATERIALS AND METHODS}

\section{Collection, culture and verification of naïve bryozoans}

To reduce the possibility of collecting parasiteresistant bryozoans (Tops and Okamura, 2003), colonies of Fredericella sultana were collected from a river site in Southern England where $T$. bryosalmonae-infected bryozoans had been previously obtained $\left(50^{\circ} 47^{\prime} 22^{\prime \prime} \mathrm{N}, 02^{\circ} 28^{\prime} 15^{\prime \prime} \mathrm{W}\right)$ during March 2005. Portions of the colonies or their attached substrata were glued onto $9 \mathrm{~cm}$ diameter Petri dishes using a cyanacrylate adhesive and macroinvertebrates were removed using a dissecting microscope and fine forceps. The colonies were initially maintained for 1 month at $18-19{ }^{\circ} \mathrm{C}$ in a custom-built, closed re-circulating culture system and fed a mixture of laboratory-cultured algae Cryptomonas ovata, Cholorgonium capillatum,
Rhodomonas sp. and Synura sp. (McGurk, 2005). The culture system was comprised of a backlit $25 \mathrm{~L}$ aquarium filled with Jarwoski's algal medium pumped into a circular bucket. The bucket had a central stand to clip the Petri dishes onto and an airlift to aerate the media and generate a gentle current. The outflow of the bucket returned to the aquarium.

Due to the transparent nature of the cystid associated with cultured bryozoans, overt $T$. bryosalmonae infection could be assessed by regular examination using an inverted microscope. Eight distinct colonies were selected which appeared to be parasite free. Portions of these colonies comprising of 6 zooids each were glued onto a new Petri dish using cyanacrylate adhesive and transferred to a fresh culture system. These colonies were maintained in this system for a further 4 months before the start of the transmission experiment. During this time the growing colonies were regularly examined for signs of $T$. bryosalmonae infection using an inverted microscope. At approximately monthly intervals, 5 zooids were removed from different areas of each of the colonies, DNA was extracted using a magnetic miniprep kit (ABGene, $\mathrm{UK}$ ), quantified using a nanodrop spectrophotometer (Nanodrop Technologies, USA), and examined for the presence of $T$. bryosalmonae using PCR and the primers $5 \mathrm{~F}$ and $6 \mathrm{R}$ (Kent et al. 1998) following the recommended cycling conditions at both 35 and 40 thermocycles. Portions of collected bryozoans exhibiting overt $T$. bryosalmonae infection were used as positive controls. Immediately prior to the exposure experiments, further control colonies were obtained by removing relatively substantial portions of the naïve colonies ( $>20$ zooids) from 4 discrete areas of the Petri dish. To encourage the adherence and growth of these pieces, netting $(0.75 \mathrm{~mm}$ diameter mesh) was glued over the Petri dishes. The removed colony fragments were introduced into the space between the netting and the dishes, which were subsequently inverted and placed into the original culture system.

\section{Infection of brown trout}

Brown trout Salmo trutta eggs, obtained from a commercial hatchery, were transferred to the Aquatic Research Facility at the University of Stirling and hatched. This facility is specific pathogen-free, and uses temperature-controlled, dechlorinated, mains tap water to feed experimental $25 \mathrm{~L}$ flow-through tanks at a rate of $0.5 \mathrm{~L} \mathrm{~min}^{-1}$. The trout were fed a proprietary diet and grown to $\sim 7 \mathrm{~g}$. Prior to exposure, 12 fish were killed by an overdose of benzocaine followed by severing of the spinal cord just behind the head, kidney samples were taken and tested using PCR and primers 5F, 6R. To further validate the T. bryosalmonae naïve status of the fish, a portion of the posterior kidney of these fish was fixed 
in formalin and immunohistochemically stained using the T. bryosalmonae-specific monoclonal antibody mAb P01 (Aquatic Diagnostics, Stirling, UK) following the manufacturer's protocol.

Using the procedure of McGurk et al. (2006) a total of 110 brown trout were exposed twice on consecutive days to water containing T. bryosalmonae spores released from infected bryozoan colonies collected during the above sampling. Fifty of these trout were transferred to a separate tank for the transmission experiment, the other 60 being used to monitor the progression of spore development within the fish. Monitoring was started 2 weeks postexposure and all fish maintained at $18{ }^{\circ} \mathrm{C}$. Six of these fish were killed on a weekly basis, kidneys removed and fixed in neutral buffered formalin, embedded in paraffin wax, sectioned and stained using immunohistochemistry with mAb P01 and mAb B4. The $\mathrm{mAb} \mathrm{B} 4$ was previously developed against the sporogonic stage of the parasite (Morris et al. 1997). Immunohistochemistry using $\mathrm{mAb} \mathrm{B} 4$ was conducted as for mAb P01 except that the mAb was used as neat hybridoma supernatant rather than reconstituted.

Transmission of Tetracapsuloides bryosalmonae to naïve Fredericella sultana

At the time when the brown trout were first noted to possess multicellular sporogonic stages and spores as verified by immunohistochemistry, water from the tank of 50 infected fish was introduced into the system containing naïve $F$. sultana continuously for 6 weeks $\left(0.51 \mathrm{~h}^{-1}\right)$ using a peristaltic pump while aquarium water was introduced into the system containing the control colonies. During this period all of the bryozoans were routinely examined on a weekly basis for overt $T$. bryosalmonae infection using a dissecting microscope.

\section{Confirmation of T. bryosalmonae infection in exposed colonies}

A portion of $F$. sultana colony, comprising 3 zooids with putative $T$. bryosalmonae spore sacs within it was excised and the DNA isolated using a magnetic mini-prep kit (ABGene, UK). The DNA was then examined using PCR, as above, using specific primers $5 \mathrm{~F}$ and $6 \mathrm{R}$. The entire DNA of the control colonies was also extracted and tested using PCR and these primers.

A further portion of the infected colony, containing spores and mature spore sacs was dissected apart in a separate $5 \mathrm{~cm}$ Petri dish. The contents of this dish were then washed into a 251 flow-through aquarium containing $6 T$. bryosalmonae naïve rainbow trout $(\sim 10 \mathrm{~g})$ obtained from eggs grown in the facility. The fish were maintained for 6 weeks at $18{ }^{\circ} \mathrm{C}$ before examining for $T$. bryosalmonae infection

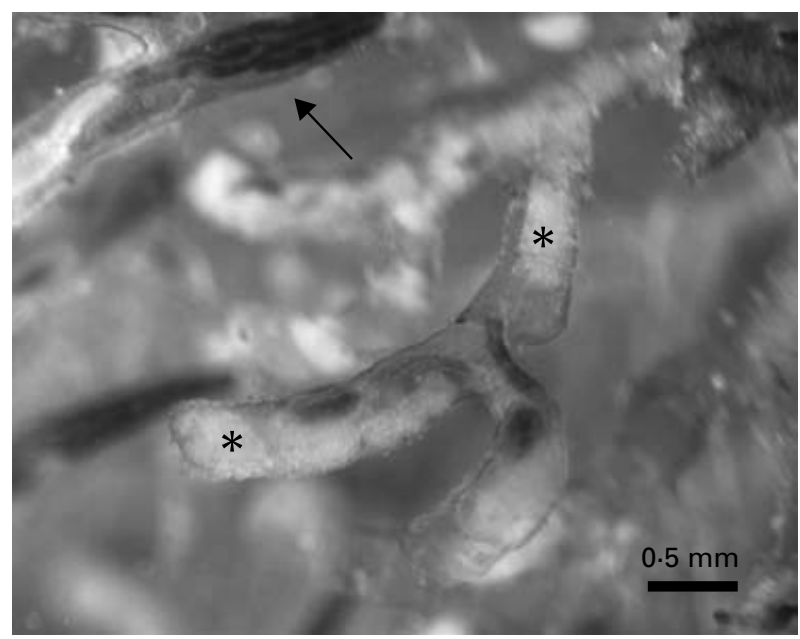

Fig. 1. Dead Fredericella sultana zooids packed with developing spore sacs, indicated with *. A healthy zooid can be observed at the top of the figure, indicated with an arrow.

using immunohistochemistry with mAb P01 as described above. Aquaria containing unexposed rainbow trout were used as a control.

RESULTS

\section{Collection of naïve bryozoans}

Large numbers of $F$. sultana were found encrusting the roots of a willow tree, situated on a riverbank. Small sections of these roots were transported to the lab for culture. The entwining and fragmentary nature of this bryozoan species, coupled with an opaque cystid meant that enumerating absolute numbers of individuals within a colony was not possible.

Evidence of infection of the $F$. sultana was first noted 1 week after collection, within the metacoel of several individuals, in the form of recognizable malacosporean spherical spore sacs. One month after collection the majority of bryozoans appeared to be infected. The infection continued in the colonies with increasing numbers of spore sacs being observed within their metacoels. After 2 months the severity of the infections, meant that for many infected individuals, the metacoel was packed with maturing sacs with the zooids either dead or misshapen with stunted lophophores and guts (Fig. 1). Statoblasts (specialized bryozoan propagules) were not produced by overtly infected colonies in contrast to those that were not infected in which they continued to develop. At the end of 3 months only bryozoans that never demonstrated parasitic infection, including those that were sampled for the transmission experiment, remained alive in the culture. These colonies continued to grow and appeared normal throughout the culture period.

From the 8 naive colonies selected for the transmission experiment only 2 survived the transfer and 


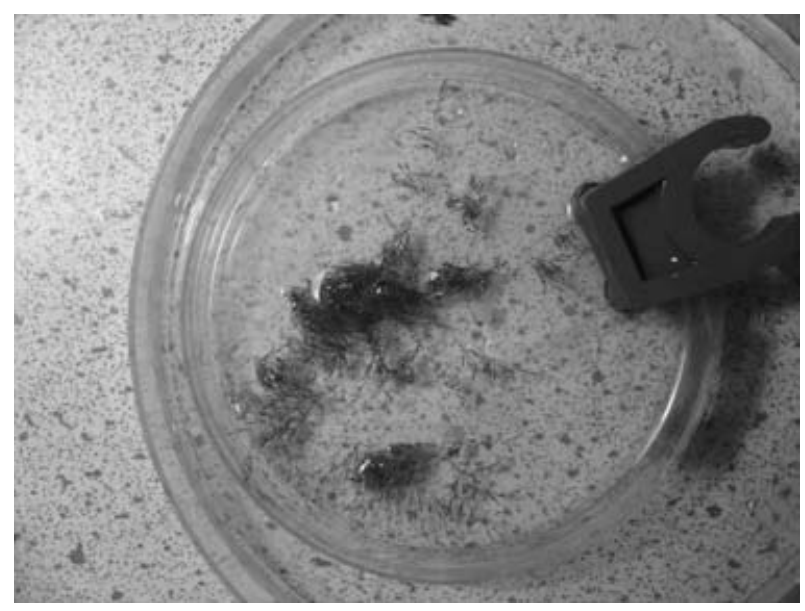

Fig. 2. Growth of experimental Fredericella sultana colonies over a $9 \mathrm{~cm}$ Petri dish immediately prior to exposure experiment.

subsequent gluing to the fresh Petri dish. These 2 colonies subsequently colonized the dish and did not show any sign of $T$. bryosalmonae infection, with PCR results repeatedly failing to demonstrate the presence of parasite DNA.

\section{Transmission of $\mathrm{T}$. bryosalmonae to brown trout}

After exposure, pre-sporogonic parasites were observed in all of the fish sampled. Initially, these were invariably noted adjacent to tubules but as the infection progressed increasing numbers of interstitial parasites were observed, together with associated inflammatory changes in the tissues surrounding them, as described in previous studies (Ellis et al. 1985; Kent and Hedrick, 1986). Intra-luminal sporogonic stages were first noted 21 days postexposure and appeared as single cells within the tubules. Spores and multi-cellular sporogonic stages were noted 9 weeks post-exposure and it is at this time that the bryozoans were exposed.

\section{Exposure of naïve Fredericella sultana to water containing brown trout}

At the time of exposure the bryozoans had colonized the majority of the Petri dish (Fig. 2). Natural fragmentation by these colonies resulted in the formation of numerous clonal individuals connected together by a common cystid.

Forty-two days post-initial exposure to water supplied from the tank of brown trout, numerous single cells of about $10 \mu \mathrm{m}$ in length were observed, swirling within the metacoel of a single bryozoan comprising of 7 zooids, followed by observable spore sacs 2 days later. Spore sacs within this individual were initially only intermittently produced, being present in the coelom for around $48 \mathrm{~h}$ before they disappeared. However, the incidence of developing sacs gradually increased so that by the second to third week of the overt infection sacs of varying sizes were being continuously observed. During this time $T$. bryosalmonae infection was noted within other areas of the colonized Petri dish. Due to the bushy nature of the cultured $F$. sultana colonies it was difficult to precisely follow development in the majority of the infected individuals and we could not accurately determine the level of infection. However, some branches of bryozoan had adhered and grown along the plastic, aiding in the repeated examination of the infection.

Spore sac development during the overt infection progressed as follows. From the beginning of the overt infection single cells were always observed in the metacoel of an infected individual. These cells formed aggregations that floated within the bryozoan's metacoel. The smallest of these was composed of only 2 or 3 cells, but much larger aggregates were observed containing numerous cells. These aggregates gradually resolved themselves into spherical bodies (spore sacs) onto which masses of cells remained attached. As the spore sacs matured, increasing in size, so the attached cells disappeared from their surface resulting in the sacs appearing uniformly spherical. The sacs then ruptured releasing mature spores into the metacoel where they were presumably released by the host into the environment. Statoblast production ceased in those individuals displaying the overt infection, while in apparently healthy parts of the colony their development continued.

During the experiment, the infection only affected a minority of individual bryozoans and occurred in parts of the colonies that were still attached to noninfected individuals through a common cystid. Those colonies grown in the separate culture system did not show any signs of infection with subsequent PCR examination of these colonies failing to amplify $T$. bryosalmonae DNA. PCR of the experimentally infected colonies produced a product of the expected size. In addition, the rainbow trout exposed to the dissected colonies developed clinical signs of PKD, with moderate kidney swelling and pre-sporogonic parasites within their kidneys in contrast to the control fish.

\section{DISCUSSION}

This study has demonstrated that Tetracapsuloides bryosalmonae can be transmitted to a bryozoan host from infected brown trout, thus resolving speculation regarding the role of a salmonid in this parasite's life-cycle. Furthermore, fish to bryozoan to fish transmission was achieved, indicating that the parasite can cycle between these hosts indefinitely without the need for an additional host.

For the transmission experiment it was important that the hosts were known to be free of infection prior 
to the study. Although specific pathogen-free brown trout eggs were used, the bryozoans obtained for the trial were collected from a $T$. bryosalmonae enzootic river so there is a possibility that they were infected prior to the experimental exposure. The presaccular development of T. bryosalmonae in Fredericella sultana involves proliferating, amoeboid stages that are distributed throughout an infected colony (Morris and Adams, 2006a). If these stages were present within the original bryozoan fragments used in the transmission experiment it would be expected that all of the subsequent colonies derived from these would also be infected. Therefore, we believe that the steps taken to verify the naïve status of these colonies, such as an extended quarantine period ( 5 months), regular PCR analysis of zooids and co-culture of the original colony and substantive colony fragments were adequate to demonstrate the absence of any covert or latent infection. PCR analysis of the control bryozoans also did not demonstrate infection, as expected if the original colonies were naïve. Further more, only a proportion of the exposed colonies became overtly infected, suggesting that the bryozoans became infected after natural colony metacoelomic fragmentation had occurred on the dish.

While identification of the precise stage infecting bryozoans was not determined, it is reasonable to assume that this was a spore derived from an infected fish. Spores were present within the tubules of the brown trout used to monitor the infection at the time of the experimental exposure, and recognizable malacosporean spores have been previously reported from the urine of $T$. bryosalmonae-infected fish (Hedrick et al. 2004). Earlier studies to naturally transmit $T$. bryosalmonae from fish to bryozoans have failed. However, none of these transmission trials precisely timed the experimental exposures to when fish could be expected to shed mature spores i.e. when spores were observed in kidney tubules. The trials being conducted when only sporogonic stages were recognized (Morris et al. $2002 a, b$; Tops et al. 2004). This suggests that failure to elicit infection was the result of infective spores not being present within the salmonids at the time of exposure. Numbers of mature spores in the urine increase towards the end of the clinical disease (Hedrick et al. 2004), correlating to their visualization in the brown trout used to monitor disease progression for the transmission experiment. However, only sporogonic stages, not spores, have been regularly reported as persisting in fish after the clinical disease has subsided (Kent and Hedrick, 1986; Morris et al. 2000a). This suggests that infective spores are only produced periodically during infection and therefore timing is an important factor to achieve successful transmission. This may also explain why a previous experiment to infect bryozoans by exposure to macerated infected kidney produced a positive PCR result (Morris et al. 2002a) while subsequent attempts to infect bryozoans by this method failed (Morris et al. 2002 b; Tops et al. 2004). In theory, while feeding macerated kidney which contained spores could transmit the infection to bryozoans, nothing is known about the conditions needed for the spores to become or remain infectious, therefore such transmission methods need to be further validated.

It is notable that although infection was induced in the exposed colonies the incidence within them appeared to be relatively low. This may have been, in part, due to the use of algal media within the culture system rather than freshwater that may have adversely affected spore infectivity. Little is known about spore development and release, although studies on rainbow trout in the USA suggest it may be a rare event in diseased and recovering fish (Hedrick et al. 2004). However, the observation that Arctic charr produce large numbers of spores suggests that the quantity of spores produced in one salmonid species are not indicative for all species (Kent et al. 2000). Sporogonic stages are known to persist in fish long after they have recovered from the clinical disease and it is likely that intra or extra-piscine environmental cues may induce further sporogenesis (Kent and Hedrick, 1986; Hedrick et al. 2004). Until more is known about sporogony in the fish host, transmission to bryozoans will be difficult to optimize.

The transmission of $T$. bryosalmonae from brown trout to a bryozoan suggests that all species of salmonid that produce mature $T$. bryosalmonae spores are capable of transmitting the infection to susceptible bryozoan species. Spores have been reported from Arctic charr Salvelinus alpinus, Chinook salmon O. tshawytscha, Coho salmon O. kisutch, cutthroat trout $O$. clarki, Atlantic salmon S. salar and brown trout S. trutta (Hedrick et al. 1993). However, for rainbow trout O. mykiss, reports of spore production have been conflicting, with spores being observed in North America but not Europe (Bucke et al. 1991). This led to the suggestion that there is a European strain of the parasite and a North American one, adapted to species of Salmo and Oncorhynchus respectively (Bucke et al. 1991 ; Morris et al. 1997). Distinct genetic differences have been found to exist between $T$. bryosalmonae isolates obtained from the two continents (Henderson and Okamura, 2004) and this further supports the hypothesis of T. bryosalmonae strains adapted to indigenous salmonids. It is important that the ability of a range of salmonids to transmit the infection to bryozoans is further examined; both to verify the results of the brown trout transmission experiment and to determine precisely which species are involved in the life-cycle of this parasite.

The report of T. bryosalmonae infecting bryozoans from Cowan Lake, in Ohio where salmonids have not been found suggests that either infected bryozoans can persist and spread independently of salmonids or there is another host capable of completing the 
life-cycle (Okamura et al. 2001). The observation that high temperatures exacerbate the infection in $F$. sultana suggests that the warm waters of this water body may be detrimental to infected bryozoans and therefore to maintain the infection another host may be required. While salmonids are well documented as hosts for the parasite, there are reports of the Northern pike Esox lucuis being infected with an organism reminiscent of $T$. bryosalmonae (Seagrave et al. 1981; Bucke et al. 1991). This parasite was identified in the kidney and was ultrastructurally identical to $T$. bryosalmonae. In addition, both the extrasporogonic and intra-tubular sporogonic stages of this parasite stained with immunohistochemistry and in situ hybridization techniques developed for the detection of $T$. bryosalmonae further confirming its identity (Morris et al. $2000 a, b$ ). Esociform fish are believed to be closely related to salmonids which could help to explain how $T$. bryosalmonae infect members of both groups (Canning and Okamura, 2004). While E. lucuis does not inhabit Cowan lake, a closely related species, E. masquinongy, is stocked and therefore has the potential to act as the vertebrate host. However, data regarding T. bryosalmonae infections of Esox spp. is at present very limited and is in need of additional research.

The development of the infection in the exposed colonies correlated with that observed by McGurk et al. (2006). These authors reported that T. bryosalmonae was detrimental to the host with much of an infected colony dying during the overt infection. In the present study, all of the infected bryozoans eventually died of the infection. The development of T. bryosalmonae in fish and bryozoan hosts is closely linked to temperature, with lower temperatures reducing the impact of the disease in rainbow trout (Ferguson, 1981; Clifton-Hadley et al. 1987; Gay et al. 2001; de Kinkelin and Loriot, 2002). This is thought to be due to elevated temperatures influencing the rate of parasite proliferation within the host, with the parasite continuing to replicate until the host is either able to mount an effective immune response or the temperature is lowered (Morris et al. 2005). The relatively high constant temperature at which the collected bryozoans were cultured during the quarantine period appeared to permit unregulated proliferation of the parasite, eventually resulting in the death of the infected hosts. This suggests that in the wild, during long, hot summers overtly infected bryozoans would regress and die while those infected later in the season, when temperatures were beginning to fall, would survive either remaining infected until the following year or producing infected over-wintering statoblasts. This correlates with the known epidemiology of the parasite both in brown trout populations, where fish are infected in early summer (June) and spores are detected 2-3 months later (Ellis et al. 1985; Clifton-Hadley and Feist, 1989; Morris and Adams, present study) and in bryozoans, where infected $F$. sultana populations are present throughout the winter but, in hot summers, the prevalence of infected colonies appears to be reduced, making them difficult to identify from some PKD enzootic sites (Gay et al. 2001; Okamura et al. 2001).

While the bryozoan $F$. sultana overwinters as a living colony, other species of freshwater bryozoans regress and survive as statoblasts. It has been postulated that these asexual propagules may harbour the infection, allowing temporal survival of the parasite over-winter and enhance the dissemination of the parasite when they are released from infected colonies (Okamura, 1996; Okamura et al. 2001; Henderson and Okamura, 2004; Tops et al. 2004). Dispersal of statoblasts through waterfowl has been suggested as the original route of introduction of $T$. bryosalmonae from North America into Europe (Henderson and Okamura, 2004). Such dispersal also correlates with the diverse nature of habitats that $T$. bryosalmonae-infected bryozoans have been identified from, including water bodies with no known salmonids present (Okamura and Wood, 2002). However, in all malacosporean infections of bryozoans examined to date, statoblast production is either markedly reduced or ceases, while attempts to hatch those statoblasts obtained from infected colonies have failed (Okamura, 1996; Canning et al. 2002; Morris et al. 2002 b; McGurk, 2005). However, this does not preclude successful infection of statoblasts which form prior to the overt infection as suggested by Tops and Okamura (2005). As such while the role of statoblasts from infected bryozoans cannot be discounted, it appears that a principal route for the spread and maintenance of the parasite in bryozoans is through exposure to spores released from native salmonids. Therefore, the farming of native salmonids and restocking of salmonid fisheries are likely to increase the levels of parasite in endemic areas.

In addition to waterfowl transporting infected statoblasts, translocation of T. bryosalmonae to new water bodies could occur through the introduction of infected salmonids either through anadromous fish that have migrated off course or stocking activities. The stocking of infected fish has been suggested as a mechanism to account for the spread of PKD in Swiss brown trout populations (Wahli et al. 2002). The original intercontinental translocation of the parasite pre-dates fisheries activities (Henderson and Okamura, 2004) and may have occurred through species of susceptible bryozoans and salmonids such as Artic charr that have natural distributions spanning the northern hemisphere. The remarkable ecological plasticity of some salmonids such as brown trout would further facilitate the distribution of the parasite to a diverse range of habitats while intra-clonal propagation through fragmentation of bryozoan colonies may assist the establishment of the 
parasite into new water bodies by increasing the spread of infected bryozoans within a body. This in turn would increase the spatial pattern of spore release thus increasing the likelihood of more fish becoming infected. Intraclonal propagation may also allow the parasite to be maintained and proliferate for extended periods within a lake or river without the need for another host (Morris and Adams, $2006 b$ ). However, this would rely on environmental conditions that would permit the infection to persist whilst not killing the bryozoan host.

While the number of malacosporean species reported from bryozoan hosts is increasing (Tops et al. 2005), malacosporean-like parasites have also been reported from non-salmonid fish such as cyprinids (Voronin, 1993). Tetracapsuloides bryosalmonae is the first malacosporean for which an alternation of host has been demonstrated indicating that the life-cycles of other malacosporeans may also require a bryozoan and fish host. This cycling between an invertebrate and vertebrate host is consistent with the other myxozoan class Myxosporea where at least some of the species alternate between an annelid and fish.

The authors would like to thank Niall Auchinachie for fish husbandry. This research was funded by a grant from the Biotechnology and Biological Sciences Research Council (grant no: BBC5050241) awarded to D. J.M. and A. A.

\section{REFERENCES}

Anderson, C. L., Canning, E. U. and Okamura, B. (1999). Molecular data implicate bryozoans as hosts for PKX (Phylum Myxozoa) and identify a clade of bryozoan parasites within the Myxozoa. Parasitology 199, 555-561.

Bucke, D., Feist, S. W. and Clifton-Hadley, R. S. (1991). The occurrence of proliferative kidney disease (PKD) in cultured and wild fish: further investigations. Fournal of Fish Diseases 14, 583-588.

Canning, E. U., Curry, A., Feist, S. W., Longshaw, M. and Okamura, B. (2000). A new class and order of myxozoans to accomodate parasites of bryozoans with ultrastructural observations on Tetracapsula bryosalmonae (PKX organism). Fournal of Eukaryotic Microbiology 47, 456-468. doi:10.1111/j.15507408.2000.tb00075.x

Canning, E. U. and Okamura, B. (2004). Biodiversity and evolution of the Myxozoa. Advances in Parasitology 56, 43-131.

Canning, E. U., Okamura, B. and Curry, A. (1996). Development of a myxosporean parasite Tetracapsula bryozoides gen. $\mathrm{n}$ et sp. $\mathrm{n}$ in Cristatella mucedo (Bryozoa: Phylactolaemata). Folia Parasitologica 43, 249-261.

Canning, E. U., Tops, S., Currie, A., Wood, T. S. and Okamura, B. (2002). Ecology, development and pathogenicity of Buddenbrockia plumatellae Schröder 1910 (Myxozoa, Malacospora) (syn. Tetracapsula bryozoides) and establishment of Tetracapsuloides n. gen. for Tetracapsula bryosalmonae. Fournal of Eukaryotic Microbiology 49, 280-295. doi:10.1111/j.1550-7408.2002.tb00371.x
Chilmonczyk, S. and Monge, D. (1999). Flow cytometry as a tool for assessment of the fish cellular immune response to pathogens. Fish and Shellfish Immunology $\mathbf{9}$, 319-333.

Clifton-Hadley, R. S. and Feist, S. W. (1989).

Proliferative kidney disease in brown trout Salmo trutta: further evidence of a myxosporean aetiology.

Diseases of Aquatic Organisms 6, 66-103.

Clifton-Hadley, R. S., Richards, R. H. and Bucke, D. (1987). Proliferative kidney disease (PKD) in rainbow trout Salmo gairdneri: further observations on the effects of water temperature. Aquaculture 55, 165-171.

de Kinkelin, P. and Loriot, B. (2001). A water temperature regime which prevents the occurrence of proliferative kidney disease (PKD) in rainbow trout, Oncorhynchus mykiss (Walbaum). Fournal of Fish Diseases 24, 489-493. doi:10.1046/j.13652761.2001.00312.x

Ellis, A. E., McVicar, A. H. and Munro, A. L. S. (1985). Proliferative kidney disease in brown trout Salmo trutta L. and Atlantic salmon, Salmo salar L., parr; histopathological and epidemiological observations. Fournal of Fish Diseases 8, 447-459.

Feist, S. W. (1988). The stickleback (Gasterosteus aculeatus) and PKD in salmonids-culprit or innocent bystander? Bulletin of the European Association of Fish Pathologists 8, 94-96.

Feist, S. W. and Bucke, D. (1993). Proliferative kidney disease in wild salmonids. Fisheries Research 17, 51-58. doi:10.1016/0165-7836(93)90006-S

Feist, S. W., Longshaw, M., Canning, E. U. and Okamura, B. (2001). Induction of proliferative kidney disease (PKD) in rainbow trout Onchorhynchus mykiss via the bryozoan Fredericella sultana infected with Tetracapsula bryosalmonae. Diseases of Aquatic Organisms 45, 61-68.

Feist, S. W., Peeler, E. J., Gardiner, R., Smith, E. and Longshaw, M. (2002). Proliferative kidney disease and renal myxosporidiosis in juvenile salmonids from rivers in England and Wales. Fournal of Fish Diseases 25, 451-458. doi:10.1046/j.1365-2761.2002.00361.x

Ferguson, H. W. (1981). The effects of water temperature on the development of proliferative kidney disease in rainbow trout, Salmo gairdneri Richardson. Fournal of Fish Diseases 4, 175-177.

Ferguson, H. W. and Needham, E. A. (1978). Proliferative kidney disease in rainbow trout Salmo gairdneri Richardson. Fournal of Fish Diseases 1, 91-108.

Gay, M., Okamura, B. and de Kinkelin, P. (2001). Evidence that infectious stages of Tetracapsula bryosalmonae for rainbow trout Oncorhynchus mykiss are present throughout the year. Diseases of Aquatic Organisms 46, 31-40.

Hedrick, R. P., Baxa, D. V., de Kinkelin, P. and Okamura, B. (2004). Malacosporean-like spores in urine of rainbow trout react with antibody and DNA probes to Tetracapsuloides bryosalmonae. Parasitology Research 92, 81-88. doi: 10.1007/ s00436-003-0986-3

Hedrick, R. P., Kent, M. L. and Toth, R. J. (1986). Myxosporeans detected in non-salmonid fishes from waters enzootic for proliferative kidney disease (PKD). Bulletin of the European Association of Fish Pathologists 6, 32-35. 
Hedrick, R. P., MacConnell, E. and de Kinkelin, P. (1993). Proliferative kidney disease of salmonid fish. Annual Review of Fish Diseases 3, 277-290. doi:10.1016/0959-8030(93)90039-E

Henderson, M. and Okamura, B. (2004). The phylogeography of salmonid proliferative kidney disease in Europe and North America. Proceedings of the Royal Society of London, B 271, 1729-1736. doi:10.1098/rspb.2004.2677

Kent, M. L. and Hedrick, R. P. (1985). Transmission of the causative agent of proliferative kidney disease (PKD) with the blood and spleen of infected fish; further evidence that the PKX parasite belongs to the phylum Myxozoa. Bulletin of the European Association of Fish Pathologists 5, 39-42.

Kent, M. L. and Hedrick, R. P. (1986). Development of the PKX myxosporean in rainbow trout Salmo gairdneri. Diseases of Aquatic Organisms 1, 169-182.

Kent, M. L. and Hedrick, R. P. (1987). Effects of cortisol implants on the PKX myxosporean causing proliferative kidney disease in rainbow trout Salmo gairdneri. Fournal of Parasitology 73, 455-461.

Kent, M. L., Khattra, J., Hervio, D. M. L. and Devlin, R. H. (1998). Ribosomal DNA sequence analysis of isolates of the PKX myxosporean and their relationship to members of the genus Sphaerospora. Fournal of Aquatic Animal Health 10, 12-21. doi:10.1577/1548-8667(1998)010<0012: $\mathrm{RDSAOI}>2.0 . \mathrm{CO} ; 2$

Kent, M. L., Khattra, J., Hedrick, R. P. and Devlin, R. H. (2000). Tetracapsula renicola n.sp. (Myxozoa: Saccosporidae); the PKX myxozoan-the cause of proliferative kidney disease of salmonid fishes. Fournal of Parasitology 86, 103-111.

Kent, M. L., Whitaker, D. J. and Margolis, L. (1993). Sphaerospora oncorhynchi n.sp. (Myxosporea: Sphaerosporidae) from the kidney of sockeye salmon (Onchorynchus nerka) in British Columbia and its possible relationship to the myxosporean causing proliferative kidney disease. Canadian Fournal of Zoology 71, 2425-2430.

Lom, J. and Dyková, I. (2006). Myxozoan genera: definition and notes on taxonomy, life-cycle terminology and pathogenic species. Folia Parasitologica $\mathbf{5 3}, 1-36$.

Longshaw, M., Feist, S. W., Canning, E. U. and Okamura, B. (1999). First identification of PKX in bryozoans from the United Kingdom - molecular evidence. Bulletin of the European Association of Fish Pathologists 19, 146-148.

MacConnel, E. and Smith, C. (1990). Non-salmonid fish inhabiting a hatchery water supply enzootic for proliferative kidney disease infected with one myxosporean, Myxobilatus spp. Bulletin of the European Association of Fish Pathologists 10, 149-151.

McGurk, C. (2005). Culture of malacosporeans (Myxozoa) and development of control strategies for proliferative kidney disease. Ph.D. thesis, Institute of Aquaculture, University of Stirling, UK.

McGurk, C., Morris, D. J., Auchinachie, N. A. and Adams, A. (2006). Development of Tetracapsuloides bryosalmonae in bryozoan hosts (as examined by light microscopy) and quantitation of infective dose to rainbow trout (Oncorhynchus mykiss). Veterinary Parasitology 135, 249-257. doi:10.1016/j.vetpar. 2005.07.022

Morris, D. J. and Adams, A. (2006a). Proliferative, presaccular stages of Tetracapsuloides bryosalmonae (Myxozoa: Malacosporea) within the bryozoan host Fredericella sultana (Bryozoa: Phylactolaemata).

Fournal of Parasitology (in the Press).

Morris, D. J. and Adams, A. (2006b). Transmission of freshwater myxozoans during the asexual propagation of invertebrate hosts. International Fournal for Parasitology 36, 371-377.

Morris, D. J., Adams, A., Feist, S. W., McGeorge, J. and Richards, R. H. (2000a). Immunohistochemical and PCR studies of wild fish for Tetracapsula bryosalmonae (PKX), the causative organism of proliferative kidney disease. Fournal of Fish Diseases 23, 129-135. doi:10.1046/j.1365-2761.2000.00227.x

Morris, D. J., Adams, A. and Richards, R. H. (1997). Studies of the PKX parasite in rainbow trout via immunohistochemistry and immunogold electron microscopy. Fournal of Aquatic Animal Health 9, 265-273. doi:10.1577/1548-8667.

(1997)009<0265:SOTPPI > 2.3.CO ;2

Morris, D. J., Adams, A. and Richards, R. H. (2000b). In situ hybridization identifies the gill as a portal of entry for PKX (Phylum Myxozoa), the causative agent of proliferative kidney disease in salmonids. Parasitology Research 86, 950-956.

Morris, D. J., Ferguson, H. W. and Adams, A. (2005). Severe, chronic proliferative kidney disease (PKD) induced in rainbow trout Oncorhynchus mykiss held at a constant $18{ }^{\circ} \mathrm{C}$. Diseases of Aquatic Organisms 66, 221-226.

Morris, D. C., Morris, D. J. and Adams, A. (2002a). Molecular evidence of release of Tetracapsula bryosalmonae, the causative organism of proliferative kidney disease from infected salmonids into the environment. Fournal of Fish Diseases 25, 501-504. doi:10.1046/j.1365-2761.2002.00352.x

Morris, D. J., Morris, D. C. and Adams, A. (2002b). Development and release of a malacosporean (Myxozoa) from Plumatella repens (Bryozoa: Phylactolaemata). Folia Parasitologica 49, 25-34.

Okamura, B. (1996). Occurrence, prevalence and the effects of the myxozoan Tetracapsula bryozoides parasitic in the freshwater bryozoan Cristatella mucedo (Bryozoa: Phylactolaemata). Folia Parasitologica 43, 262-266.

Okamura, B., Anderson, C. L., Longshaw, M., Feist, S. W. and Canning, E. U. (2001). Patterns of occurrence and 18ssu rDNA sequence variation of PKX (Tetracapsula bryosalmonae) the causative agent of salmonid Proliferative Kidney Disease. Fournal of Parasitology 87, 379-385.

Okamura, B. and Wood, T. S. (2002). Bryozoans as hosts for Tetracapsula bryosalmonae, the PKX organism. Fournal of Fish Diseases 25, 469-475. doi:10.1046/ j.1365-2761.2002.00376.x

Seagrave, C. P., Bucke, D. and Alderman, D. J. (1980). Ultrastructure of a Haplosporean like organism: the possible causative agent of proliferative kidney disease in rainbow trout. Fournal of Fish Biology 16, 453-459. 
Seagrave, C. P., Bucke, D., Hudson, E. B. and McGregor, D. (1981). A survey of the prevalence and distribution of proliferative kidney disease in England and Wales. Fournal of Fish Diseases 4, 437-439.

Tops, S., Baxa, D. V., McDowell, T. S., Hedrick, R. P. and Okamura, B. (2004). Evaluation of malacosporean life cycles through transmission studies. Diseases of Aquatic Organisms 60, 109-121.

Tops, S., Curry, A. and Okamura, B. (2005). Diversity and systematics of the Malacosporea (Myxozoa). Invertebrate Biology 124, 285-295. doi:10.1111/ j.1744-7410.2005.00026.x

Tops, S. and Okamura, B. (2003). Infection of bryozoans by Tetracapsuloides bryosalmonae at sites endemic for salmonid proliferative kidney disease. Diseases of Aquatic Organisms 57, 221-226.
Tops, S. and Okamura, B. (2005). Malacosporean parasites (Myxozoa, Malacosporea) of freshwater bryozoans (Bryozoa, Phylactolaemata): a review. Denisia 28, 287-298.

Voronin, V. N. (1993). PKX like organism in common carp during swim-bladder inflammation: further evidence of an association with the myxosporean Sphaerospora renicola. Bulletin of the European Association of Fish Pathologists 13, 127-129.

Wahli, T., Kneusel, R., Bernet, D., Segner, H., Pugovkin, D., Burkhardt-Holm, P., Escher, M. and Scmidt-Posthaus, H. (2002). Proliferative kidney disease in Switzerland: current state of knowledge. Fournal of Fish Diseases 25, 491-500. doi:10.1046/j.1365-2761.2002.00401.x 